The data were recorded by questioner and analysis with spss 11.5. Frequency distribution, mean, standard deviation, $T$ student, Chi square, Mann Whitney and fisher tests were used.

Results During the study, 150 newborn were enrolled. Ninety five of $150(63.3 \%)$ were male and the other were female. The mean gestational age was $30.24 \pm 2.76$ (minimum 24 maximum 40), the mean birth weight was1423.76 \pm 539.25 (minimum 560 maximum 3470 ). The mortality rate was $42.7 \%$ (64 of 150 ). The most common complications were nosocomial sepsis $(36.4 \%)$, pulmonary hemorrhage $(18.4 \%)$, pneumothorax $(16.4 \%)$, intracranial hemorrhage (10.4\%) and pneumonia (8.4\%).

Conclusions In this study the mortality rate and complications were high. Therefore pay attention to these patients is essential especially nursing patient ratio, indeed as sepsis is very common usage of disposable equipment is necessary.

\section{RELATIONSHIP BETWEEN BONE AGE AND PUBERTAL BREAST STAGE TO BONE BIOMARKERS AND BONE MINERAL DENSITY IN HEALTHY BRAZILIAN FEMALE ADOLESCENTS}

doi:10.1136/archdischild-2012-302724.0428

${ }^{1}$ TBL Goldberg, ${ }^{2} \mathrm{CMT}$ Fortes, ${ }^{2} \mathrm{CS}$ Kurokawa, ${ }^{3} \mathrm{CC}$ Silva, ${ }^{2} \mathrm{MR}$ Moretto, ${ }^{4} \mathrm{HRDC}$ Nunes. 'Department of Pediatrics, Post Graduation Program in Gynecology, Obstetrics and Mastology; ${ }^{2}$ Department of Pediatrics, Clinical and Experimental Pediatric Research Center, Botucatu School of Medicine, São Paulo State University - UNESP, Botucatu; ${ }^{3}$ Department of Physical Education, University of North Paraná, Jacarezinho; ${ }^{4}$ Statistical Consultant, Botucatu School of Medicine, São Paulo State University - UNESP, Botucatu, Brazil

Background and Aims Bone metabolism involves understanding many factors, especially during puberty, when bone turnover is significant and the bone mass peak must be achieved as a protective factor of future bone health. The objective was to evaluate the behavior of formation and resorption bone biomarkers (BB) in function of biological maturation in female adolescents.

Methods Evaluation of formation and resorption $\mathrm{BB}$, osteocalcin (OC), bone alkaline phosphatase (BAP) and carboxyterminal telopeptide (S-CTx) by correlating them with bone mineralization, bone age and pubertal development in healthy female adolescents. Seventy-two volunteers were subdivided into groups according to chronological age/bone age (BA): 10-11 years $(n=12), 12-13$ years $(n=16), 14-15$ years $(n=15)$ and $16-19$ years $(n=29)$. The following were evaluated: weight $(\mathrm{kg})$, height $(\mathrm{m})$, BMI $\left(\mathrm{kg} / \mathrm{m}^{2}\right)$, calcium intake (3-day $24 \mathrm{~h}$ food recalls ( $\mathrm{mg} /$ day), puberty events (Tanner stages), serum OC $(\mathrm{ng} / \mathrm{mL}), \mathrm{BAP}(\mathrm{U} / \mathrm{L}), \mathrm{S}-\mathrm{CTx}(\mathrm{ng} / \mathrm{mL})$ and bone mineral density $(\mathrm{BMD})$ as calculated by DXA $\left(\mathrm{g} / \mathrm{cm}^{2}\right)$ in the spine (L1-L4), proximal femur and whole body. The project was approved by the UNESP Ethics Committee.

Results $\mathrm{BB}$ showed similar behaviors, with higher mean values for 10-12 years and when adolescents were in the B2-B3 Pubertal Maturation Stage (B2: BAP $=110.16 \mathrm{U} / \mathrm{L}, \mathrm{OC}=33.81 \mathrm{ng} / \mathrm{mL}, \mathrm{S}-\mathrm{CT} x=1.66$ $\mathrm{ng} / \mathrm{mL}$ and $\mathrm{B} 3: \mathrm{BAP}=136.50 \mathrm{U} / \mathrm{L}, \mathrm{OC}=39.15 \mathrm{ng} / \mathrm{mL}$ and $\mathrm{S}-\mathrm{CT} \mathrm{x}=1.88$ $\mathrm{ng} / \mathrm{mL} ; \mathrm{p}<0.001)$. Mean $\mathrm{BB}$ values decreased with advancing $\mathrm{BA}$ and pubertal maturity.

Conclusions $\mathrm{BB}$ values showed parallelism with peak height velocity and significant negative correlation with $\mathrm{BMD}$ in the different evaluated sites, with chronological and $\mathrm{BA}$; higher $\mathrm{BMD}$ values correlated with lower bone biomarker values.

\section{THE LEVEL OF ADOLESCENT DEPRESSION AMONG TEENS IN SERBIA}

doi:10.1136/archdischild-2012-302724.0429

'S Tomic, ${ }^{2}$ I Djuric Filipovic, ${ }^{3} \mathrm{D}$ Filipovic, ${ }^{1} \mathrm{M}$ Ilic. ${ }^{1}$ Health Centre Savski Venac; ${ }^{2}$ US Medical School; '3Emergency Hospital Department Pediatric, Belgrade, Serbia
Background and Aims The alarming number of young people tend to develop the typical clinical picture of depression. Aim is to determine the presence of depression among young people in Serbia on a representative sample.

Methods Socio-epidemiological surveys and the Beck Depression Inventory Assessment, completed by 2049 students of upper secondary school.

Results The feeling of loss of energy and fatigue was the most common symptom, $40.1 \%$ of young people answered yes to this question $0.34 .4 \%$ of respondents have difficulty concentrating and making decisions, and $31.6 \%$ state that what is bothering them is a feeling of sadness and despondency.

The feeling of decreased self-esteem occurs to $24.5 \%$ of respondents, $22.2 \%$ of them have no more interest in usual activities. Feeling excessive guilt is confirmed by $21.7 \%$ of students, and $19.8 \%$ think in the pessimistic way about the future. Problems with appetite have $16.5 \%$, and $15.6 \%$ have sleeping problems. $9.0 \%$ of young people often think about death or suicide.

Conclusions All these data, especially the one about thinking about suicide, tell how frequent depressive symptoms are and how much thay can be dangerous. Although depressed mood is one of the developmental characteristics of adolescence, this many young people who show a tendency to develop this disorder is certainly alarming and require additional efforts in order to counteract this trend.

\section{BOERHAAVE'S SYNDROME (SPONTANEOUS ESOPHAGEAL RUPTURE) AN UNUSUAL SEQUALE OF A COMMON SYMPTOM}

doi:10.1136/archdischild-2012-302724.0430

F Alrefaee. Pediatrics, Adan Hospital, Kuwait, Kuwait

Boerhaave's syndrome (BS) or spontaneous esophageal rupture is rare in children. It is thought to result from a sudden increase in the intraesophageal pressure during retching combined with negative intrathoracic pressureClassically BS presents with vomiting, subcutaneous emphysema and thoaco-abdominal pain (Mackler's triad).We reported a 14 year old girl who was previously well presented to a Tertiary Care Centre Emergency Department with a 24 hour history of retrosternal chest pain and upper abdominal discomfort following three days of frequent retching and intense vomiting.

She was in moderate pain and afebrile; heart rate was 100 per minute with respiratory rate 24 per minute. Palpation of both suprascapular fossae and her left axillary fossa revealed crepitus indicating the presence of subcutaneous emphysema. Auscultation of cardiorespitaory system was normal and her. Abdomen revealed mild epigastric tenderness with no rebound phenomenon, masses or organomegally.

Her chest $\mathrm{x}$ ray revealed evidence of subcutaneous emphysema and mediastinal air, an upper GI study with water soluble contrast showed extravasation of the contrast from the distal segment of the esophagus into the mediastinum compatible with the diagnosis of spontaneous esophageal rupture or Boerhaave's syndrome. She was admitted and treated conservatively with intravenous fluids, antibiotics and nil per os with resolution of her symptoms in 48hours and resolution of mediatinal air in-72 hours. Subsequent endoscopy was grossly and histologically normal.

\section{THE EFFECT OF SPORTIVE ACTIVITY ON BONE MINERAL DENSITY DURING ADOLESCENCE}

doi:10.1136/archdischild-2012-302724.0431

Y Sayar, Fi Arıkan, MA Taşar, Y Dallar Bilge. Pediatrician, Ministry of Health, Ankara Training and Education Hospital, Ankara, Turkey 
Aim Hormonal balance, genetic background, calcium/vitamin $\mathrm{D}$ metabolism, nutrition, lifestyle and physical activity are principle factors effecting bone health during puberty. The aim of the study is to evaluate the effect of regular sportive activity (SA) on bone mineral density.

Materials and methods Adolescents admitted to Department of Pediatrics with licensed regular SA (n: 55) and without regular SA (n: 56) were included in the study. Age, height, body weight, body mass index (BMI), Tanner stages, educational status of parents, mean daily calcium intake, smoking, sun exposure, total of time for watching television and playing computer and type of licensed SA were recorded. Bone mineral density $(B M D)$ was measured with a quantitative ultrasonography device.

Results BMI was higher in group without a regular SA ( $\mathrm{p}=0.024)$. Adolescents with regular SA had higher $\mathrm{BMD}$ when compared to group without a regular SA ( $\mathrm{p}=0.011)$. Vitamin $\mathrm{D}$ levels were also higher in group with SA $(p<0.001)$. Daily calcium intake did not show any significant difference between groups ( $p>0.05)$. Higher educational status of parents was significantly related with higher prevalence of SA. Vitamin intake was higher in adolescence with SA $(p=0.002)$ and smoking was more common in adolescents without regular $\mathrm{SA}$ ( $\mathrm{p}=0.023)$.

Conclusion Quantitative ultrasound can be used to evaluate the $\mathrm{BMD}$ in children. Physical activity during adolescence is important for bone growth and SA should be encouraged earlier. Especially, adolescents whose mothers had higher educational status took part in SA more frequently.

\section{NUTRITIONAL KNOWLEDGE, ATTITUDE AND PRACTICE OF HIGH SCHOOL GIRLS LIVING IN KUWAIT: A PILOT STUDY}

\section{doi:10.1136/archdischild-2012-302724.0432}

${ }^{1}$ F Alrefaee, ${ }^{2} \mathrm{M}$ Nassar, ${ }^{3} \mathrm{~S}$ Aldhafiri, ${ }^{3} \mathrm{~S}$ Alqattan, ${ }^{3} \mathrm{~A}$ Al Mutairi. ${ }^{1}$ Pediatrics, Adan Hospital, Kuwait, Kuwait; ' 2 Pediatrics, Ain Shams University, Cairo, Egypt; ${ }^{3}$ Food and Nutrition Department, Adan Hospital, Kuwait, Kuwait

Aim of the work This study was designed to study the nutritional knowledge, attitude and practice of adolescent school girls in Kuwait to assess the current situation and advise the need for directed nutritional programs.

Methods A dietary questionnaire on nutritional knowledge, food habits, eating behavior and food frequency sheet as well as anthropometric measurements were done to 72 school girls aged 15 to 17 years who were recruited from a governmental high school in Kuwait.

Results Among the studied girls nearly half stated that the family was their primary nutritional knowledge source compared to approximately one fifth who chose the internet, another one fifth were from books and journals. More than half of the studied girls had below average knowledge about different nutrients and their function. This deficient knowledge affected their food frequency sheet and limited their choices to below average in about half of cases. Their life style was less than satisfactory in over two thirds where the girls preferred sedentary activities compared to active exercise. Fortunately, only minority of the studied girls were overweight compared to three quarters having their body mass index within accepted range.

Conclusion Although there is insignificant effect of the deficient nutritional knowledge and dietary behavior of the studied high school girls on their BMI, this deficient nutritional knowledge is likely to have a negative impact on their nutritional status as future mothers as well as the nutritional status of their children to come since family is the commonest source of nutritional knowledge.

433 THE KNOWLEDGE OF SEXUAL TRANSMITTED DISEASES ADOLESCENCE IN LOW ECONOMIC LEVEL

doi:10.1136/archdischild-2012-302724.0433
MA Taşar, H Demir, Y Dallar Bilge. Pediatrics, Ministry of Health, Ankara Training and Education Hospital, Ankara, Turkey

The purpose of this work is to do a research on the level of awareness about sexually transmitted diseases (STD) of adolescence and the factors effecting it.

Method A number of adolescent at the ages of 14-17 ( $n=527)$ were asked to complete a survey questioning their level of knowledge of STDs and their sociological and demographical issues.

Data were entered into the SPSS 15.0 program and evaluated. A value of $p<0.05$ was assumed for statistical significance.

Findings $78.9 \%$ of the adolescent responded positively to the question of whether or not they are aware of the fact that diseases could be transmitted via sexual intercourse. $48.6 \%$ of the adolescent responded negatively to whether or not they knew "how the diseases are transmitted", 59.4\% responded negatively to whether or not they know "how to protect themselves from those diseases", and $67.2 \%$ responded negatively to whether or not they know "the symptoms of STDs". The count of the right answers were in increase in correlation with the education and economic level of the parents $(p<0.05)$. The results showed that $49.3 \%$ of them learned information about STDs at school and from medical institutions. $9.3 \%$ of them stated that they had intercourse in the last one-year period and $8.0 \%$ of them utilized a method of protection.

Result Awareness level of adults about STDs is inadequate. For that, schools and medical institutions, where they are inclined most to get education, should organize mass education events for them about these matters.

\section{RELATIONSHIP BETWEEN OBESITY AND 8-HYDROXY 2- DEOXY GUANOSINE AS AN OXIDATIVE MARKER IN OBESE ADOLESCENTS OF GIZA}

doi:10.1136/archdischild-2012-302724.0434

'E Abdel Hameed, ${ }^{2} \mathrm{~A}$ El Wakkad, ${ }^{3} \mathrm{NEM}$ Hassan, ${ }^{1} \mathrm{~L}$ Sherif, ${ }^{1} \mathrm{~A}$ Abd El-Shaheed, ${ }^{2} \mathrm{H}$ Sebii, ${ }^{2} \mathrm{~S}$ El Zayat. 'Child Health; ${ }^{2}$ Physiology; ${ }^{3}$ Anthropology, National Research Centre, Cairo, Egypt

Background and Aim This study was conducted to assess the relationship between obesity markers (Body mass index "BMI", fat percentage) and DNA oxidative marker 8-hydroxyl guanosine $(\mathrm{OHG})$, as a predictor for future clinical problems in obese adolescents of Giza.

Methods The study was conducted on 103 adolescents aged 13-18 years (22 boys, 81 girls). BMI was calculated as body weight $(\mathrm{kg})$ divided by height $\left(\mathrm{m}^{2}\right)$ squared and obesity was defined as BMI of 95 percentile. Fat percentage was determined by using Biological impedance technique. Oxidative stress markers as 8-hydroxyl guanosine, superoxide and gluthione were measured. The adolescents were divided according to BMI into two groups. Group I with BMI > 95 percentile and less than 97 percentile (obese) and Group $\cap$ with BMI $>97$ percentile (severely obese).

Results Significant differences were detected between the two groups of the study as regard obesity markers (BMI, fat \%) and oxidative stress markers (lipid oxidation, superoxide dismutase enzyme activity, glutathione peroxidase enzyme activity, 8-hydroxyl guanosine) $(p<0.0005)$. Significant positive correlations were detected between obesity markers and oxidative stress markers among severely obese adolescent (group II). Obesity is highly associated with states of oxidative stress in adolescents, with a positive relation with 8-hydroxy-guanosine and obesity markers and other oxidative markers.

Conclusion This marker might play an important role in the prediction of future development of some clinical diseases. 